\title{
Digital Goods Are Valued Less Than Physical Goods
}

\author{
OZGUN ATASOY \\ CAREY K. MOREWEDGE
}

\begin{abstract}
Digital goods are, in many cases, substantive innovations relative to their physical counterparts. Yet, in five experiments, people ascribed less value to digital than to physical versions of the same good. Research participants paid more for, were willing to pay more for, and were more likely to purchase physical goods than equivalent digital goods, including souvenir photographs, books (fiction and nonfiction), and films. Participants valued physical goods more than digital goods whether their value was elicited in an incentive compatible pay-what-you-want paradigm, with willingness to pay, or with purchase intention. Greater capacity for physical than digital goods to garner an association with the self (i.e., psychological ownership) underlies the greater value ascribed to physical goods. Differences in psychological ownership for physical and digital goods mediated the difference in their value. Experimentally manipulating antecedents and consequents of psychological ownership (i.e., expected ownership, identity relevance, perceived control) bounded this effect, and moderated the mediating role of psychological ownership. The findings show how features of objects influence their capacity to garner psychological ownership before they are acquired, and provide theoretical and practical insights for the marketing, psychology, and economics of digital and physical goods.
\end{abstract}

Keywords: digital goods, value, psychological ownership, perceived control

$\mathrm{T}$ he digitization of goods-their transformation into files that can be transmitted without a physical object (Belk 2013; Molesworth and Denegri-Knott 2013; Odom, Zimmerman, and Forlizzi 2011), has created exciting improvements in the lives of consumers and their welfare (Cohen et al. 2017; Goldfarb, Greenstein, and Tucker 2015). Digital goods can be bought online, consumed immediately, and used without worry for their degradation or

Ozgun Atasoy (ozgun.atasoy@unibas.ch) is a postdoctoral research associate in the department of marketing of the Faculty of Business and Economics at the University of Basel, Peter Merian-Weg 6, CH-4052 Basel, Switzerland. Carey K. Morewedge (morewedg@bu.edu) is a professor of marketing in the Questrom School of Business at Boston University, Rafik B. Hariri Building, 595 Commonwealth Avenue, Boston, MA 02215. This research is based on the first author's dissertation. Please direct correspondence concerning this manuscript to Ozgun Atasoy.

Vicki Morwitz served as editor and Kristin Diehl served as associate editor for this article.

Advance Access publication October 9, 2017 loss. All of a person's digital books, documents, music, photographs, and videos can be stored in one pocket-sized device, providing the individual access to a library of content anywhere at any time. Digital goods have proliferated widely. Digital photographs, for instance, were first commercialized in 1990 and now are taken more often than print photographs (Mintel 2009; Said 1990). Similar advances in technology have given rise to the widespread digitization of many other consumer goods, including books, magazines, newspapers, music, movies, and even academic journals. Digital goods play a critical role in our modern, increasingly liquid and experiential world (Bardhi, Eckhardt, and Arnould 2012; Gilovich, Kumar, and Jampol, 2015).

Despite the many advantageous features of digital goods, physical goods appear to retain greater allure. Print books are still the dominant format, and there is no upward trend in the market share of e-books (Pew Research Center 2016). With regard to home entertainment spending, physical sales (e.g., Blu-ray) are continuing to grow alongside sales of video on demand (Digital Entertainment Group 2016). Demand is growing for physical copies of photographs 
people already own in a digital format (Amazon 2016; Perez 2016).

We suggest that despite the many advantages conferred by digital goods, comparable versions of physical goods are valued more. We report five experiments demonstrating that lower value is ascribed to digital goods than physical goods even before they are acquired. We find that the greater capacity for physical than digital goods to garner psychological ownership underlies this difference in their value. In line with our process account, manipulating antecedents and consequents of psychological ownership (i.e., expected ownership, identity relevance, and psychological control) moderates this difference in value. Furthermore, our findings show that features of a good or object, as opposed to factors latent in the mind of the consumer, can influence whether psychological ownership is established for a good before it is acquired.

\section{THEORETICAL BACKGROUND}

In interviews and qualitative observational research, people appear to prefer physical goods to digital goods, and a variety of theories have been proposed to explain this preference. Drawing from interviews of music collectors, Giles, Pietrzykowski, and Clark (2007) suggest that the greater social identity-signal and legacy potential found in physical recording formats (e.g., LPs and CDs) might increase their value relative to digital recording formats (e.g., MP3s). Others have posited that physical goods may be valued more due to their permanence and greater ability to serve as a reminder of the past. People report perceiving digital objects as unstable, transient, quick, spontaneous, and ephemeral, and physical goods to be more permanent and stable (Petrelli and Whittaker 2010). In addition, digital objects are perceived to be less intimate and incapable of expressing personal memories. Other qualitative research suggests that the greater ease of establishing an emotional connection, association with the self, or attachment to physical goods imbues them with greater value due to their greater permanence, their tangibility, and the ability to touch them (Belk 2013; Siddiqui and Turley 2006). Not all such theorists are in agreement with regard to the direction of this effect. Some have argued that this preference is spurious; that people form attachments to digital products in a way similar to the way they form attachments to physical products (Lehdonvirta 2012). Digital goods arguably may even have greater value to particular consumer segments due to their liquid form (e.g., global nomads; Bardhi et al. 2012).

Each of these theories has its merits, but we propose that this preference is largely driven by the greater capacity of physical than digital goods to garner psychological ownership. The materiality of physical goods makes them easier for people to touch, manipulate, and move compared to digital goods, and these actions critically advantage physical goods in the capacity to garner psychological ownership (Furby 1980; Peck and Shu 2009; Pierce, Kostova, and Dirks 2003). Consequently, physical goods should benefit more from the value-enhancing effects of psychological ownership than similar digital goods. We unpack our theory in more detail below.

First, manipulating and touching objects establishes perceived control, a key antecedent to psychological ownership, in a variety of contexts. People touch an object in a public space to establish that it is in their possession or to establish it as their territory and deter others from using it (Werner, Brown, and Damron 1981). High-status people touch low-status people to establish their control over them (Henley 1973). Even imagined touch can increase the perception that one has claim to a good (Peck, Barger, and Webb 2013). Holding a good establishes both a feeling of ownership and sense of possession over it (Reb and Connolly 2007). Because physical goods are by definition material goods, they are easier to directly hold, touch, manipulate, and thus establish control over (Peck and Shu 2009; Pierce et al. 2003; Reb and Connolly 2007) than immaterial digital goods. Because perceived control is a key antecedent to psychological ownership, physical goods may thus have a greater capacity to garner psychological ownership than digital goods.

Once psychological ownership is established for a good, an attachment to that good is formed (i.e., a possession-self link), whereby the good is associated with and incorporated into the self-concept (Beggan 1992; Belk 1988; Chatterjee, Irmak, and Rose 2013; Morewedge and Giblin 2015; Weiss and Johar 2013). Because people tend to entertain unrealistically positive perceptions of themselves, a consequence of this association of a good with the self is an increase in its perceived value (Beggan 1992; Dommer and Swaminathan 2013; Morewedge et al. 2009; Perkins and Forehand 2012; Shu and Peck 2011). Because of their greater capacity to garner psychological ownership, physical goods should benefit more from the value-enhancing effects of this possession-self link-this mere ownership effect-and should be valued more than equivalent digital goods.

Differences in the capacity of digital and physical goods to garner psychological ownership should influence their perceived value even at the point of acquisition. In many cases, people extend psychological ownership to goods even before those goods are owned (Kim and Johnson 2014; Peck et al. 2013; Reb and Connolly 2007; Sen and Johnson 1997). Actions common to the acquisition process, such as imagining that one owns a good, touching a good, or holding a good in one's physical possession, are sufficient to increase perceived psychological ownership for a good before its acquisition (Kim and Johnson 2014; Peck et al. 2013; Reb and Connolly 2007; Sen and Johnson 1997). Moreover, whether one expects to own a good in 
the future trumps actual ownership in the establishment of psychological ownership for the good (Ericson and Fuster 2011; List 2003).

\section{HYPOTHESES AND EXPERIMENTS}

We propose that digital goods are valued less than equivalent physical goods, and that this difference is due to the greater capacity of physical goods to garner psychological ownership than digital goods. We base our hypothesis on the assumption that the materiality of physical goods imbues consumers with a greater sense of perceived control over physical goods than equivalent digital goods, which should induce a greater perception of psychological ownership for physical than digital goods (Henley 1973; Peck et al. 2013; Peck and Shu 2009; Pierce et al. 2003; Werner et al. 1981). As a consequence of the greater psychological ownership with which physical goods are imbued, a stronger possession-self link is formed. The valueenhancing effects of this association (i.e., mere ownership effect) should then induce a higher valuation for physical goods than for equivalent digital goods. As psychological ownership can be established before goods are acquired (Kim and Johnson 2014; Peck et al. 2013; Reb and Connolly 2007; Sen and Johnson 1997), this difference in value between physical and digital goods should be observed even at the stage of acquisition, when consumers are considering whether to acquire goods (e.g., buy or rent them).

An overview of our general theoretical model is illustrated in figure 1. Solid lines indicate explicit assumptions that we test directly. Dashed lines indicate implicit assumptions that we test indirectly.

Of course, digital goods are not always valued less than similar physical goods. The antecedents and consequents of psychological ownership that are implicit in our model (indicated by dashed lines in figure 1) suggest at least three boundary conditions under which this difference in value should be mitigated. First, as expected ownership is an antecedent of psychological ownership (Ericson and Fuster 2011), the greater value ascribed to physical than digital goods should be smaller when people do not expect to own or keep a good (e.g., rented goods; tested in experiment 3 ). Second, as the value-enhancing effects of psychological ownership are predicated on the association it creates between the good and the self (Morewedge and Giblin 2015), the greater value of physical than digital goods should be greater for goods easily incorporated into the self-concept and smaller for goods that are difficult to incorporate into the self-concept (e.g., identity-relevant and identityirrelevant goods, respectively; tested in experiment 4). Third, because perceived control is an antecedent of psychological ownership (Furby 1980; Peck and Shu 2009; Pierce et al. 2003), the greater value of physical than
FIGURE 1

THEORETICAL MODEL

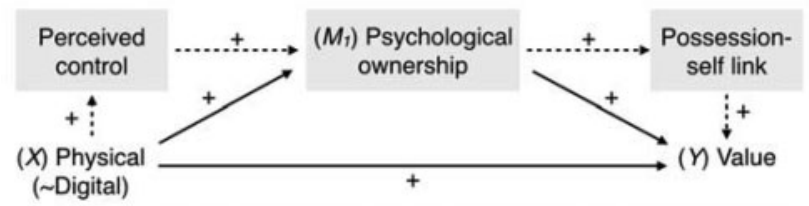

digital goods should be diminished for people who deem having control over their external world to be relatively unimportant (i.e., people low in need for control); the difference in the materiality and perceived controllability of the goods should be weaker determinants of the degree to which these consumers feel psychological ownership for a good (tested in experiment 5).

All five experiments we report directly test our proposed basic effect: that people value physical goods more than digital goods (e.g., books, movies, photographs). Our research complements earlier observational research by empirically testing this difference in valuation. We propose that people ascribe greater value to physical goods than to analogous digital goods. More formally,

H1: All else equal, people value physical goods more than digital goods.

We test our first hypothesis in five experiments using three value-elicitation mechanisms: whether people will pay more for physical than digital goods in a pay-whatyou-want paradigm (PWYW; experiment 1), are willing to pay more for physical than for digital goods (WTP; experiments 2, 3, and 5), and report higher purchase intention for physical than for digital goods (PI; experiment 4).

Second, we hypothesize that consumers value physical goods more than digital goods because the materiality of physical goods imbues them with a greater capacity to garner psychological ownership (i.e., $M_{1}$ in figure 1). Formally,

H2: A greater capacity to garner psychological ownership underlies the greater value ascribed to physical than digital goods.

We test our proposed psychological ownership mechanism in three ways. First, in experiments 2 and 5 we directly measured whether differences in psychological ownership for physical and digital goods mediate the difference in value they are ascribed. Second, in experiments 3 and 4 we indirectly tested our psychological ownership mechanism by examining whether manipulating one of its antecedents and one of its consequents (i.e., expected ownership and the identity relevance of a good, respectively) would moderate the greater value ascribed to physical than 
digital goods. Third, in experiment 5 we tested whether individual differences in the importance of perceived control-an antecedent to psychological ownership-would moderate the mediating effects of psychological ownership on the greater value ascribed to physical than digital goods.

The moderated mediation paradigm in experiment 5 also allowed us to test whether perceived control indeed plays a pivotal role in the greater capacity of physical than digital goods to garner psychological ownership. Formally,

H3: The perception that greater control can be exerted over physical than digital goods underlies the greater capacity for physical than digital goods to garner psychological ownership.

In a moderated mediation design, we predicted that people lower in need for control (NFC), who do not place a premium on having control over their environment relative to people higher in NFC, would be less likely to exhibit greater psychological ownership for physical than digital goods, and would consequently be less likely to ascribe them different value.

We also test alternative plausible mechanisms for the difference in the value ascribed to physical and digital goods, including differences in their perceived production cost (experiments 1 and 5), resale value (experiments 1 and 3 ), consumption utility (experiment 2), permanence (experiment 2), and retail price (experiment 5). We acknowledge that several of these factors are likely to orthogonally contribute to existing differences in the value ascribed to physical and digital goods; however, we suggest that none can account for the unique and important role of psychological ownership.

Our research also elucidates two related phenomena. First, we explore whether an internal feature of an object (e.g., its materiality) influences its capacity to garner psychological ownership. The determinants of psychological ownership identified to date have all been intrapersonal psychological phenomena. Second, our research tests a novel moderator determining whether psychological ownership for a good is established before the good is acquired.

We report all measures, stimuli, and participants collected, as well as all participant exclusions for every experiment in this article.

\section{EXPERIMENT 1: PWYW FOR DIGITAL AND PHYSICAL SOUVENIRS}

We first tested whether people would ascribe greater value to a physical good than its digital counterpart in an incentive-compatible field experiment using a "pay-whatyou-want" design (PWYW; Gneezy et al. 2012). Tourists visiting Old North Church in Boston, Massachusetts, which has a symbolic association with the American Revolution (Fischer 1994), were given a physical or digital souvenir photograph of themselves with a research assistant dressed as Paul Revere. Physical photographs were taken with an instant camera (akin to a Polaroid). Digital photographs were taken with a 13 megapixel camera. Participants were then solicited for a donation equivalent in value to their photograph $(\geq \$ 0)$ to the historical society maintaining the church. After making their donation, participants estimated the production cost of their photograph. We predicted that participants would pay more for the physical than digital souvenir photograph, a difference that would not be explained by any difference in their production cost estimates.

An additional benefit of this design was that it controlled for differences in resale value. None of our participants were famous, so both physical and digital photographs had no secondary market value (i.e., $\$ 0$ resale value).

\section{Method}

Participants. Eighty-six tourists visiting the Old North Church in Boston, Massachusetts (53 women; $\mathrm{M}_{\mathrm{age}}=$ $39.40, \mathrm{SD}_{\text {age }}=13.50$ ), saw a sign reading "Take a picture with Paul Revere" and volunteered to participate in exchange for a photograph with a costumed historical figure (i.e., a research assistant dressed in period attire as Paul Revere).

Procedure. A research assistant, dressed as Paul Revere, approached tourists one at a time at the entrance of the church courtyard. He asked, "Would you like a picture with Paul Revere? You can pay whatever you want for it, including \$0. The proceeds will go to the Old North Foundation, the historical association maintaining this site." (Upon request, participants were offered an information sheet explaining its activities.) Each new participant was recruited after the previous participant completed the study. During recruitment, the research assistant did not mention the format of the photograph.

Tourists who volunteered were (unknowingly) randomly assigned to receive a physical or digital souvenir photograph with "Paul Revere." At this point, participants were shown a camera by a second experimenter, and learned the format of the photograph-physical or digital—as it was taken. This photographer stood at a table about 5 meters from the entrance of the church courtyard during recruitment. He took physical photographs with a Fujifilm Instax Mini 90 instant camera, and took digital photographs with an LG G2 smartphone 13 megapixel digital camera. The focal subjects in each photograph were the participant and "Paul Revere." Participants in the physical photograph condition were given the instant-printed photograph immediately, as it began to develop. Participants in the digital photograph condition were immediately emailed the digital photograph. 
Participants then made their donations before they could examine the photograph. The instant photograph took a few minutes to develop, and the email containing the digital photograph took a few minutes to arrive. In the interim, all participants indicated their email address, donation amount, gender, and age in a paper-and-pencil survey. Finally, participants were asked to flip the page and estimate "the approximate cost of all study materials, per photograph, to the researchers (wages, materials, and costume)."

\section{Results}

Due to the high frequency of $\$ 0$ donations, donation amounts were highly skewed (skewness $=2.72>1.96$ in the physical condition; skewness $=3.06>1.96$ in the digital condition), suggesting that nonparametric or transformed analyses were the most appropriate methods (Wilcox 2010) to analyze the PWYW responses. For nonparametric tests, we used the raw responses for donations. For parametric tests, we first transformed donations with a square-root transformation. We illustrate the distribution of donations by condition in figure 2 .

As predicted, tourists in the physical condition (Median $=\$ 3.00 ; M$ of the SQRT of payments $=\$ 1.57$, $\mathrm{SD}$ of the SQRT of payments $=.98$ ) paid more than did tourists in the digital condition (Median $=\$ 1.00 ; M$ of the $\mathrm{SQRT}$ of payments $=\$ 1.02, \mathrm{SD}$ of the SQRT of payments $=1.13$; Mann-Whitney $U=1,182, z=2.32, p=.02, r=$ .25 ). Cost estimates were not skewed (skewness $=.22<$ 1.96 in the physical condition; skewness $=|-.007|<1.96$ in the digital condition) and did not differ across conditions $\left(M_{\text {physical }}=\$ 2.90, \mathrm{SD}_{\text {physical }}=1.49 ; M_{\text {digital }}=\$ 2.89\right.$, $\left.\mathrm{SD}_{\text {digital }}=1.37 ; t<1\right)$. Estimated cost was not a significant predictor of the square root of payment when included as a covariate in an ANCOVA $(F(1,82)=.008, p=.93$, $\left.\eta_{\mathrm{p}}^{2}<.001\right)$, nor did its inclusion influence the main effect of condition (i.e., digital vs. physical) on how much participants paid for the photographs $(F(1,82)=5.89, p=.02$, $\left.\eta_{\mathrm{p}}^{2}=.07\right)$.

\section{Discussion}

Tourists in this field experiment paid more for a physical than digital souvenir photograph. The nonresalable nature of the photographs and the equivalent estimates of their production costs suggest that this difference cannot be attributed to differences in their resale value or production costs. The results thus provide strong evidence for our hypothesis that consumers value physical goods more than analogous digital goods in an incentive-compatible setting (hypothesis 1). It is possible, however, that these effects are idiosyncratic to photographs. People may consider it unusual to pay for smartphone pictures. We directly addressed this alternative explanation and the generalizability of our finding in experiment 2 , by testing the value
FIGURE 2

TOURISTS' DONATIONS FOR A SOUVENIR (PWYW)
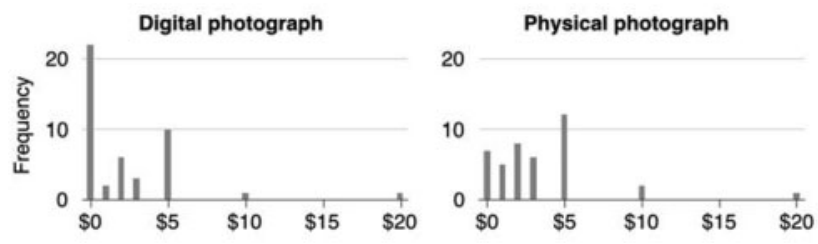

ascribed to two other digital and physical goods that consumers regularly purchase (i.e., books and films) with a different value elicitation procedure: willingness to pay.

\section{EXPERIMENT 2: PSYCHOLOGICAL OWNERSHIP AS UNDERLYING MECHANISM}

We directly tested in experiment 2 whether the greater capacity for physical than for digital goods to garner psychological ownership (hypothesis 2) underlies their greater perceived value. We measured psychological ownership directly to test whether it might mediate the relationship between product format and value as elicited with willingness to pay (WTP). We also examined whether two alternative potential mechanisms might drive the higher valuation of physical than digital goods: the perceived permanence of those goods (McCourt 2005; Petrelli and Whittaker 2010) and their anticipated consumption utility. People may believe that a physical book is more valuable because they are more likely to be able to use it in twenty years, for instance, or that it is more enjoyable to read from the printed page than from an e-reader.

\section{Method}

Participants. Four hundred one Amazon Mechanical Turk workers (168 women, $\mathrm{M}_{\text {age }}=32.68, \mathrm{SD}_{\text {age }}=10.08$ ) completed the experiment for $\$ 0.50$.

Procedure. Each participant first reported how much he or she would be willing to pay for a physical or digital copy of either a book (i.e., Harry Potter and the Sorcerer's Stone; printed or Kindle) or a movie (i.e., The Dark Knight; DVD or iTunes). WTP was elicited with an openended response box. Participants simply entered the maximum amount of money that they were willing to pay for the good.

As measures of psychological ownership for the good (Peck and Shu 2009; Shu and Peck 2011), all participants indicated the extent to which they would "feel a very high degree of personal ownership of it," "feel like I own it," 
and "feel like it is mine" if they purchased that good on three seven-point scales with endpoints of "strongly disagree" (1) and "strongly agree" (7) $(\alpha=.94)$. Participants then completed measures of permanence (adapted from Pena-Marin and Bhargave 2016) by indicating the extent to which they agreed with four statements indicating that the particular format of the book or movie was permanent, stable, durable, and lasting on seven-point scales with the endpoints "strongly disagree" (1) and "strongly agree" (7) $(\alpha=.93)$. Participants then completed an anticipated consumption enjoyment measure by indicating the extent to which they would enjoy watching the movie or reading the book in the format they were assigned to on a seven-point scale with the endpoints "strongly disagree" (1) and "strongly agree" (7). These scales were completed in the same order for all participants (i.e., ownership, then permanence, then anticipated consumption enjoyment); scale items were presented in random order.

\section{Results and Discussion}

Willingness to Pay. WTP was not skewed, except for values ascribed to digital books ( skew $_{\text {movie, digital }}=1.27<$ 1.96 , skew $_{\text {book, digital }}=5.63>1.96$, skew movie, $_{\text {physical }}=$ $.68<1.96$, skew book, $_{\text {physical }}=1.15<1.96$ ); therefore, it was not transformed. The transformed data yield results similar to those reported below.

Valuation was examined in a 2 (product type: movie, book) $\times 2$ (product format: physical, digital) betweensubjects ANOVA, which revealed a significant main effect of product format $\left(F(1,397)=21.41, p<.001 ; \eta_{\mathrm{p}}^{2}=.05\right)$ on WTP such that participants were WTP more for physical $(M=\$ 9.30, \mathrm{SD}=6.55)$ than digital goods $(M=\$ 5.96$, $\mathrm{SD}=7.60)$. It did not reveal a significant main effect of product type $\left(M_{\mathrm{book}}=\$ 8.32, \mathrm{SD}_{\mathrm{book}}=8.82 ; M_{\text {movie }}=\right.$ $\$ 6.93, \mathrm{SD}_{\text {movie }}=5.28 ; F(1,397)=3.05, p=.08 ; \eta_{\mathrm{p}}^{2}=$ .008 ) or a significant product format by product type interaction $\left(F(1,397)=.80, \mathrm{p}=.37 ; \eta_{\mathrm{p}}^{2}=.002\right)$. As illustrated by figure 3 , simple contrasts revealed that participants were WTP more for the physical format of the book $(M=$ $\$ 9.59, \mathrm{SD}=7.25)$ than the digital format $(M=\$ 6.94$, $\left.\mathrm{SD}=10.13 ; F(1,397)=6.91, p=.009 ; \eta_{\mathrm{p}}^{2}=.02\right)$, and more for the physical format of the movie $(M=\$ 8.98$, SD $=5.72)$ than the digital format $(M=\$ 5.07, \mathrm{SD}=4.06$; $\left.F(1,397)=15.35, p<.001, \eta_{\mathrm{p}}^{2}=.04\right)$.

Process Measures. Psychological ownership was examined in a 2 (product type: movie, book) $\times 2$ (product format: physical, digital) between-subjects ANOVA, which revealed main effects of product format $\left(M_{\text {physical }}=6.04\right.$, $\mathrm{SD}_{\text {physical }}=1.03 ; M_{\text {digital }}=4.69, \mathrm{SD}_{\text {digital }}=1.57 ; F(1$, $\left.397)=102.72, p<.001 ; \eta_{\mathrm{p}}^{2}=.21\right)$ and product type $\left(M_{\text {book }}=5.53, \mathrm{SD}_{\text {book }}=1.35 ; M_{\text {movie }}=5.20, \mathrm{SD}_{\text {movie }}=\right.$ $\left.1.60 ; F(1,397)=4.02, p=.046 ; \eta_{\mathrm{p}}^{2}=.01\right)$ but no significant product format by type interaction $(F(1,397)=.60$,
FIGURE 3

WILLINGNESS TO PAY FOR DIGITAL AND PHYSICAL GOODS

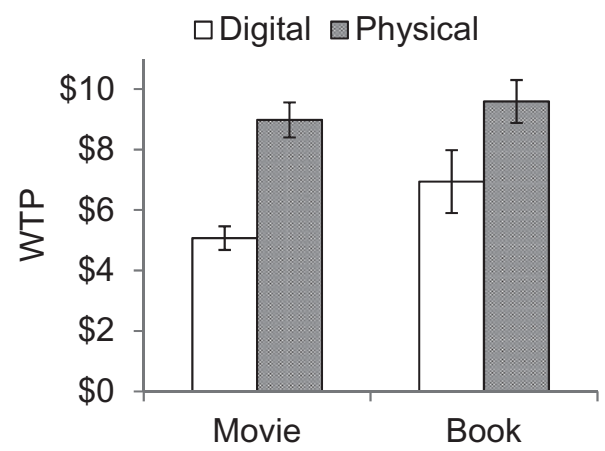

NOTE.-Participants were WTP more for popular movies and books in physical than digital formats in experiment 2 . Error bars indicate \pm 1 SEM.

$\left.\mathrm{p}=.44 ; \eta_{\mathrm{p}}^{2}=.001\right)$. Simple contrasts revealed that for both products, participants reported higher psychological ownership for physical than digital goods. They felt greater psychological ownership for the physical format of the book $(M=6.12, \mathrm{SD}=.88)$ than the digital format $(M=$ $\left.4.88, \mathrm{SD}=1.48 ; F(1,397)=43.52, p<.001 ; \eta_{\mathrm{p}}^{2}=.10\right)$, and greater psychological ownership for the physical format of the movie $(M=5.96, \mathrm{SD}=1.17)$ than the digital format $(M=4.51, \mathrm{SD}=1.64 ; F(1,397)=59.92, p<$ $\left..001, \eta_{\mathrm{p}}^{2}=.13\right)$.

Permanence was examined in a 2 (product type: movie, book) $\times 2$ (product format: physical, digital) betweensubjects ANOVA, which revealed main effects of product format $\left(M_{\text {physical }}=5.72, \mathrm{SD}_{\text {physical }}=1.11 ; M_{\text {digital }}=4.76\right.$, $\left.\mathrm{SD}_{\text {digital }}=1.50 ; F(1,397)=51.98, p<.001 ; \eta_{\mathrm{p}}^{2}=.12\right)$ and product type $\left(M_{\mathrm{book}}=5.43, \mathrm{SD}_{\mathrm{book}}=1.25 ; M_{\mathrm{movie}}=\right.$ $5.05, \mathrm{SD}_{\text {movie }}=1.52 ; F(1,397)=6.84, p=.009 ; \eta_{\mathrm{p}}^{2}=$ .02) but no product format by product type interaction $\left(F(1,397)=.11, p=.75 ; \eta_{\mathrm{p}}^{2}<.001\right)$. Simple contrasts revealed that participants rated the physical format of the book $(M=5.87, \mathrm{SD}=.92)$ to be more permanent than the digital format $(M=4.96, \mathrm{SD}=1.39 ; F(1,397)=23.53$, $p<.001 ; \eta_{\mathrm{p}}^{2}=.06$ ), and the physical format of the movie $(M=5.57, \mathrm{SD}=1.26)$ to be more permanent than the digital format $(M=4.58, \mathrm{SD}=1.58 ; F(1,397)=28.59, p<$ $\left..001, \eta_{\mathrm{p}}^{2}=.07\right)$.

Enjoyment was examined in a 2 (product type: movie, book) $\times 2$ (product format: physical, digital) betweensubjects ANOVA, which revealed no main effect of product format $\left(M_{\text {physical }}=5.79, \mathrm{SD}_{\text {physical }}=1.20 ; M_{\text {digital }}=\right.$ $\left.5.84, \mathrm{SD}_{\text {digital }}=.97 ; F(1,397)=.19, p=.67 ; \eta_{\mathrm{p}}^{2}<.001\right)$, product type $\left(M_{\text {book }}=5.77, \mathrm{SD}_{\text {book }}=1.16 ; M_{\text {movie }}=5.85\right.$, $\left.\mathrm{SD}_{\text {movie }}=1.02 ; F(1,397)=.54, p=.46 ; \eta_{\mathrm{p}}^{2}=.001\right)$, or product format by product type interaction $(F(1,397)=$ $\left..01, p=.91 ; \eta_{\mathrm{p}}^{2}<.001\right)$. Simple contrasts revealed that participants rated the physical $(M=5.83, \mathrm{SD}=1.12)$ and the digital format of the book $(M=5.80, \mathrm{SD}=1.03)$ as 
producing similar consumption utility $(F(1,397)=.15$, $\left.p=.70 ; \eta_{\mathrm{p}}^{2}<.001\right)$. They also rated the physical $(M=$ $5.74, \mathrm{SD}=1.28)$ and the digital format of the movie $(M=$ $5.87, \mathrm{SD}=.92$ ) as producing similar consumption utility $\left(F(1,397)=.05, p=.82, \eta_{p}^{2}<.001\right)$.

As product format had no effect on enjoyment, enjoyment was dropped from the list of potential mediators. Since the effect of format did not depend on product type (the product format by product type interaction was not significant for all of the dependent measures), we collapsed across product type in our mediation.

Mediation Analysis. We conducted a mediation analysis, simultaneously testing whether the differences observed in psychological ownership or permanence would mediate the observed differences in value for physical and digital goods. As recommended by Hayes (2013), we examined confidence intervals (CI) using 5,000 bootstrap iterations. The analysis included both product types. Product format was coded as 0 when the participant was randomly assigned to consider a digital product, and 1 when the participant was randomly assigned to consider a physical product.

As predicted, the indirect effect through ownership (.96, 95\% CI [.21, 2.08]) was significant, but the indirect effect through permanence $(.20,95 \%$ CI $[-.32, .68])$ was not significant. The direct effect of product format was significant $(2.18,95 \%$ CI $[.62,3.74])$, indicating partial mediation by ownership. The direction of the effects in the mediation analysis (figure 4) indicates that the physical format led to stronger establishment of psychological ownership, which in turn contributed to higher WTP.

\section{EXPERIMENTS 3 AND 4: BOUNDARIES PREDICTED BY PSYCHOLOGICAL OWNERSHIP}

In experiments 3 and 4, we tested our psychological ownership account (hypothesis 2) of the greater value ascribed to physical than digital goods by testing if the effect is bounded by moderating well-established antecedents (experiment 3) and consequents (experiment 4) of psychological ownership. While both experiments indirectly examined our psychological ownership hypotheses, their experimental designs could have provided unique evidence for or against our process account, beyond the test of multiple mediators conducted in experiment 2 (Zhao, Lynch, and Chen 2010).

Our first test of moderation examined expected ownership, as perceived ownership of a good in the present is contingent on whether one expects to own that good in the future (Ericson and Fuster 2011; List 2003). We manipulated expected future ownership in experiment 3 by asking business students how much they were WTP to rent or buy either a digital or physical textbook for a course in which

\section{FIGURE 4}

\section{PARALLEL MEDIATION MODEL OF WILLINGNESS TO PAY FOR DIGITAL AND PHYSICAL GOODS}

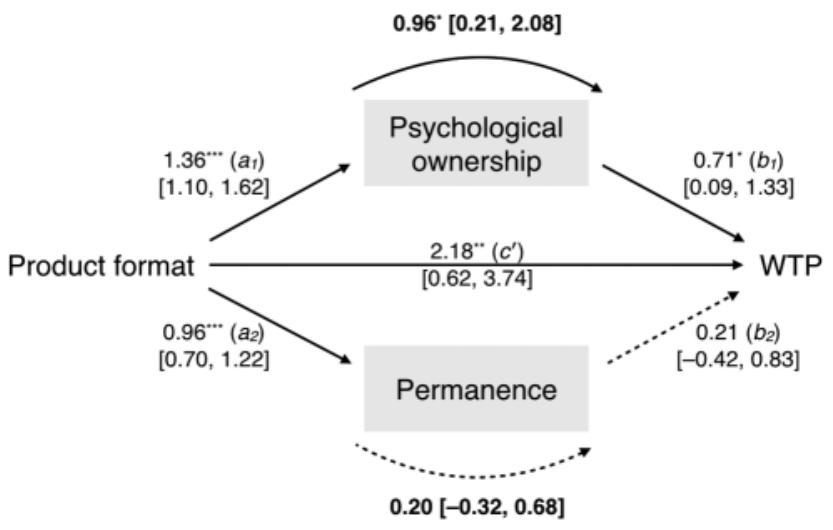

NOTE.-Psychological ownership partially mediated the effect of product format on WTP in experiment 2. Numbers annotating curved arrows indicate indirect effects. Dashed lines indicate paths that are not statistically significant. Bracketed numbers indicate $95 \%$ Cls. ${ }^{*} p<.05,{ }^{* *} p<.01,{ }^{* * *} p<.001$.

they were enrolled. Because rented textbooks are returned at the end of the semester, students randomly assigned to consider a rented textbook should not expect to own it. While we did not measure psychological ownership directly in experiment 3, renting should thus impair the establishment of psychological ownership for a textbook relative to purchasing it. As we posit that psychological ownership is not readily established with digital products regardless of whether they are purchased or rented, our theory suggests the difference between psychological ownership for digital and physical books should thus be smaller if they are rented than if they are purchased. Consequently, the difference in WTP for digital and physical books should be smaller if they are rented than if they are purchased.

To address differences in the potential resale value of physical and digital textbooks, we told all students that the textbook was in the last year of its current edition and would have $\$ 0$ resale value after they finished the course. These instructions mitigated the possibility that students would be WTP more for the physical version because they could later sell it as a used book and recoup its price. Note that this addresses the potential for resale in a different manner than experiment 1 , which used products with no resale value (i.e., personal souvenir photographs).

Our second test of moderation examined the boundary effect of a consequent of psychological ownership by manipulating the strength of the value-enhancing association between a good and the self (for a review, see Morewedge and Giblin 2015). In experiment 4, we tested whether the difference in value ascribed to physical and digital goods would be moderated by the identity relevance of goods, which influences the ease of establishing such an 
association between a good and the self (Dommer and Swaminathan 2013). Participants indicated the identity relevance of several film series (e.g., Star Wars, The Fast and the Furious), and then indicated their purchase intention for either a DVD or a digital copy of The Empire Strikes Back, a film from the Star Wars series. Because an association between a good and the self- a possession-self linkis less likely to develop when a good is irrelevant to the consumer's identity (e.g., a plain undershirt) than when the good is highly relevant to the consumer's identity (e.g., a university t-shirt; Dommer and Swaminathan 2013; Morewedge and Giblin 2015; Weiss and Johar 2013, 2016), we predicted that the difference between purchase intentions for a DVD and digital copy of The Empire Strikes Back would be higher for participants who more strongly identified with the Star Wars series relative to other movie series. The use of purchase intention in this experiment had the added benefit of empirically testing whether consumers also prefer physical to digital goods that are similarly priced, which is implied by the relatively limited market share of digital goods (Digital Entertainment Group 2016; Pew Research Center 2016).

\section{EXPERIMENT 3: MODERATION BY EXPECTED OWNERSHIP}

\section{Method}

Participants. Two hundred seventy-five undergraduate business majors at Boston University (168 women; $M_{\text {age }}=$ $19.56, \mathrm{SD}_{\text {age }}=3.15$ ) participated in the experiment for course credit.

Procedure. Students considered a vignette in which they had to acquire a textbook for a course in which they were currently enrolled. It specified that the textbook was "in the last year of its current edition, so it will have no resale value when the course is over."

In a between-subjects design, students reported the maximum price they would pay to either purchase the textbook or to rent the textbook for 180 days, in either a physical or digital format (i.e., a new printed copy or a digital Kindle copy of the textbook). Students indicated their WTP in an open-ended format as in experiment 2.

\section{Results}

WTP was not skewed, except for values ascribed to digital textbook purchases (skew $_{\text {rent, digital }}=1.87<1.96$, skew $_{\text {buy, }}$ digital $=2.91>1.96$, skew $_{\text {rent, }}$ physical $=1.52<$ 1.96 , skew $_{\text {buy, physical }}=1.75<1.96$ ); therefore, it was not transformed. The transformed data yield results similar to those reported below.

We examined reported WTP for a textbook with no resale value in a 2 (product format: digital, physical) $\times 2$ (ownership status: rental, purchase) between-subjects
ANOVA, which revealed significant main effects of product format $\left(M_{\text {digital }}=\$ 46.05, \mathrm{SD}_{\text {digital }}=40.15\right.$; $M_{\text {physical }}=\$ 73.50, \mathrm{SD}_{\text {physical }}=52.92 ; F(1,271)=24.33$, $\left.p<.001, \eta_{\mathrm{p}}^{2}=.08\right)$, and ownership status $\left(M_{\text {rental }}=\right.$ $\$ 52.99, \mathrm{SD}_{\text {rental }}=32.32 ; M_{\text {purchase }}=\$ 66.51, \mathrm{SD}_{\text {purchase }}=$ $\left.60.51 ; F(1,271)=5.74, p=.02, \eta_{\mathrm{p}}^{2}=.02\right)$. More important, the analysis revealed the predicted significant product format by ownership status interaction, $(F(1,271)=7.87$, $\left.p=.005, \eta_{\mathrm{p}}^{2}=.03\right)$. As illustrated by figure 5 , simple contrasts revealed that students were WTP more to purchase a physical copy of the textbook $(M=\$ 87.81, \mathrm{SD}=$ 65.02) than to rent a physical copy of the textbook $(M=$ $\$ 58.97, \mathrm{SD}=31.13, F(1,271)=13.47, p<.001$, $\left.\eta_{\mathrm{p}}^{2}=.05\right)$. By contrast, participants were not WTP more to purchase a digital copy of the textbook $(M=\$ 44.90, \mathrm{SD}=$ 46.89) than to rent a digital copy of the textbook $(M=$ $\left.\$ 47.17, \mathrm{SD}=32.61 ; F(1,271)=.08, p=.77, \eta_{\mathrm{p}}^{2}<.001\right)$. Comparing the cells across product format, we found that participants were WTP similar amounts to rent a physical or digital textbook $\left(F(1,271)=2.27, p=.13, \eta_{\mathrm{p}}^{2}=.008\right)$, whereas they were WTP more to buy a physical than digital textbook $\left(F(1,271)=29.82, p<.001, \eta_{\mathrm{p}}^{2}=.10\right)$.

\section{Discussion}

Participants were willing to pay more to own a physical copy of a textbook than a digital copy of that textbookeven though it would have no future resale value, whereas participants were not willing to pay more to rent a physical copy of that textbook than a digital copy of that textbook. As ownership increases value only for goods one expects to possess in the future (Ericson and Fuster 2011; List 2003), the results illustrate moderation of the greater value ascribed to physical than digital goods by expected ownership. Because the WTP difference disappeared when ownership was not expected, ownership appears to be a critical factor explaining the difference in the value ascribed to physical and digital goods.

Practically, these results illustrate an important boundary condition for the pricing of physical and digital goods. They suggest that consumers may not be willing to pay more for physical than digital services providing them access to consumer goods on a rental or subscription basis (e.g., movies, music, books).

\section{EXPERIMENT 4: MODERATION BY IDENTITY RELEVANCE}

\section{Method}

Participants. Four hundred one Amazon Mechanical Turk workers (177 women, two unspecified gender; $M_{\text {age }}$ $=34.95, \mathrm{SD}_{\text {age }}=11.20$ ) completed the experiment for $\$ 0.30$. 
FIGURE 5

\section{WILLINGNESS TO PAY TO RENT OR BUY A DIGITAL OR PHYSICAL TEXTBOOK}

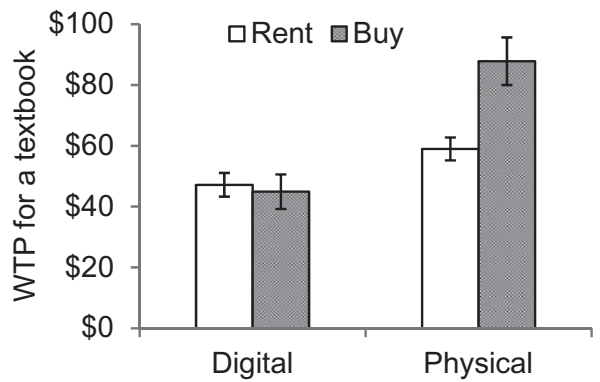

NOTE.-Participants were WTP more to buy than rent a physical copy of a textbook, but were not WTP more to buy than rent a digital copy of a textbook in experiment 3 . Error bars indicate \pm 1 SEM.

Procedure. All participants first read, "People vary on the extent to which they see different things as part of their personal self identity. For this study, please indicate the extent to which each series of movies below is part of your self." Then they indicated the extent to which they would describe 10 popular movie series as part of their selves on a seven-point scale with the endpoints "not at all part of my self" (1) and "very much part of my self" (7). The movie series were labeled: Star Wars (the science fiction movie series), Die Hard (the action movie series), Halloween (the horror movie series), James Bond (the spy movie series), Pirates of the Caribbean (the pirate movie series), Rocky (the boxing movie series), Sex and the City (the romantic comedy movie series), Step Up (the modern dance movie series), The Fast and the Furious (the automotive movie series), and The Godfather (the gangster movie series). The information in parentheses was included with the series titles as a description. Participants rated the movie series in random order.

Next, participants read a short description of the movie The Empire Strikes Back from the Star Wars series, quoted from the review aggregator website www.rottentomatoes. com. After reading the description, participants were randomly assigned to one of two conditions. Participants assigned to the physical format condition read, "Imagine that you are offered to receive today a DVD of the movie The Empire Strikes Back for \$15.99. How likely would you be to purchase the DVD?" Participants assigned to the digital condition read, "Imagine that you are offered to receive today a digital copy of the movie The Empire Strikes Back from iTunes for $\$ 15.99$. How likely would you be to purchase the iTunes movie? (An iTunes movie is downloaded online.)" All of the participants indicated their purchase likelihood on a seven-point scale with the endpoints "very unlikely" (1) and "very likely" (7). Immediate delivery was included in these descriptions to mitigate potential differences in the perceived ease of purchasing the movie in different formats or any perceived difference in the delivery of the movie.

Then, all of the participants indicated whether they already owned "a physical copy (for instance, a DVD or a Blu-ray disc) of the movie The Empire Strikes Back" or "a digital copy (for instance, from iTunes, Amazon, or Google Play) of the movie The Empire Strikes Back" and answered demographic questions.

\section{Results}

Participants reported a higher purchase intention for a physical $(M=2.57, \mathrm{SD}=1.76)$ than digital copy of The Empire Strikes Back $(M=2.20, \mathrm{SD}=1.63 ; t(399)=2.16$, $p=.03, d=.22$ ). In the analysis that follows, we tested whether identity relevance moderated this effect. We added previous ownership of the movie in both formats as statistical controls; analyses without these controls yield similar results.

To calculate the identity relevance of the Star Wars series for each participant, we used its rank among the $10 \mathrm{se-}$ ries. For instance, if a participant gave Star Wars the highest identity relevance rating out of all 10 series, that participant's rank for Star Wars was coded as 10 (if it was ranked lowest, then it was coded as 1). Mean rank numbers were assigned to ties. For instance, if a participant gave Star Wars and James Bond the same identity relevance rating, and each of the remaining eight series lower ratings, that participant's rank for Star Wars was coded as 9.5. We reasoned that relative ranking is a more sensitive measure of identity relevance than the score of Star Wars in isolation because it controls for individual differences in interpreting the identity-relevance question (alternative ways to measure identity relevance, discussed below, yield similar effects).

We tested the moderating effect of identity relevance by regressing purchase intention on product format, identity relevance, and their interaction as explanatory variables, and existing ownership of a physical and a digital copy as statistical controls. Product format was coded as in experiment 2 (i.e., digital $=0$, physical $=1$ ).

Whereas product format $(b=-.56, t(395)=-1.18, p=$ $.24,95 \%$ CI $[-1.50, .37])$ and identity relevance $(b=$ $.01, t(395)=.28, p=.78,95 \%$ CI $[-.08, .11])$ did not significantly predict purchase intention, their interaction did $(b=.13, t(395)=2.06, p=.04,95 \%$ CI $[.01, .26])$, indicating that identity-relevance moderated the relationship between product format and purchase intention. Among the statistical controls, existing ownership of a physical copy of the movie significantly predicted purchase intention $(b=$ $.56, t(395)=3.01, p=.003,95 \%$ CI $[.19, .93])$. Existing ownership of a digital copy had a marginal effect on purchase intention $(b=.49, t(395)=1.78, p=.08,95 \% \mathrm{CI}$ $[-.05,1.02])$. 
The difference between the purchase intention for the physical and digital copies increased (in favor of the physical) for participants who considered Star Wars to be more relevant to their identity than other movie series (figure 6): the conditional effect of product format on purchase intention at $-1 \mathrm{SD}$ of identity relevance (i.e., at ranking $=4.45$ ) was .02 and not statistically significant $(t(395)=.09, p=$ $.92, d=.01,95 \%$ CI $[-.43, .48])$; at the mean (i.e., at ranking $=7.01)$ it was $.36(t(395)=2.19, p=.03, d=.22$, $95 \%$ CI $[.04, .68])$; and at +1 SD (i.e., at ranking $=9.57$ ) it was $.70(t(395)=3.00, p=.003, d=.30,95 \%$ CI $[.24$, 1.15]).

The results of experiment 4 held in similar analyses using alternative coding of identity relevance, and other statistical controls. A similar regression analysis with the less sensitive raw identity-relevance ratings of Star Wars as a proposed moderator yielded a marginally significant interaction effect $b=.13, t(395)=1.16, p=.097,95 \% \mathrm{CI}$ $[-.02, .28]$, and conditional effects with a similar structure as reported above. A regression analysis with the $Z$-scored identity-relevance ratings of Star Wars as a proposed moderator, where normalization was done within individual (i.e., using the mean and standard deviation of each individual for normalizing), yielded similar results with a marginally significant interaction effect $b=.26, t(352)=$ $1.72, p=.086,95 \%$ CI $[-.04, .56]$. Finally, adding gender and age as statistical controls to the reported analyses, to account for the movie series' potentially different appeal to different demographic groups, led to similar results and these controls did not predict purchase intention $(t \mathrm{~s}<.7)$.

\section{Discussion}

Participants reported a higher purchase intention for a physical than digital copy of a popular movie, but this effect of product format was moderated by the identity relevance of the good. Participants who identified with Star Wars more than with other popular movie series exhibited a higher purchase intention for a physical than digital copy of the movie, whereas participants who identified with Star Wars less than with other popular movie series did not exhibit a higher purchase intention for a physical or digital copy of it. As identity relevance is an important precursor for the object-self associations that establish psychological ownership for goods (Dommer and Swaminathan 2013; Morewedge and Giblin 2015; Weiss and Johar 2013, 2016), its moderating effect in experiment 4 provide additional evidentiary support for our theory that psychological ownership underlies the greater value ascribed to physical than digital goods.

In addition, as value was elicited via purchase intention in this experiment, the results suggest that the greater value ascribed to physical than digital goods is not due to anchoring on different reference prices or production costs. Furthermore, it helps to elucidate how this effect might
FIGURE 6

INTENTION TO PURCHASE THE EMPIRE STRIKES BACK BY PRODUCT FORMAT AND IDENTITY RELEVANCE OF THE STAR WARS SERIES

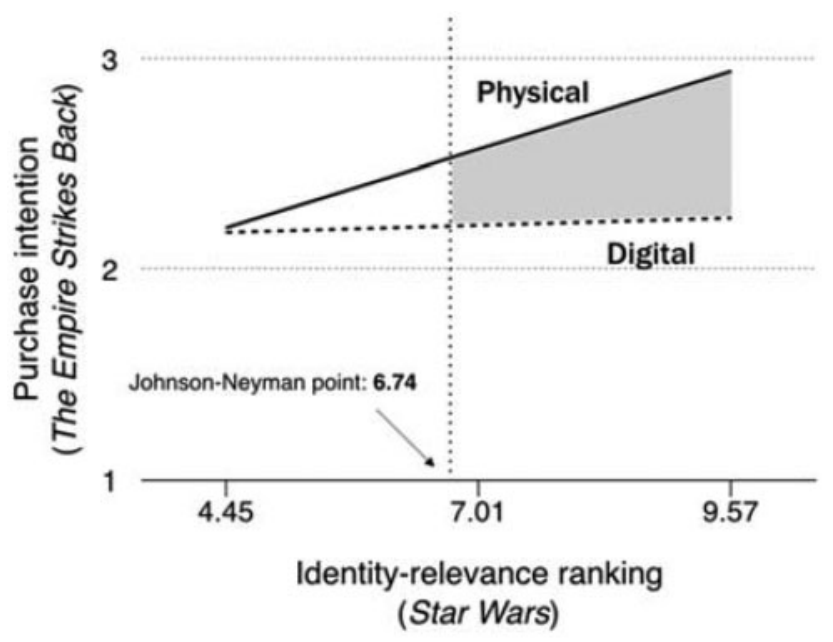

NOTE.-Participants who ranked the identity relevance of the Star Wars series higher than the Johnson-Neyman point 6.74 (54.86\%) exhibited significantly greater purchase intention for a physical than digital copy of The Empire Strikes Back.

hold when both formats are offered, and provide insight into the relatively low market share of digital goods (Digital Entertainment Group 2016; Pew Research Center 2016).

\section{EXPERIMENT 5: NEED FOR CONTROL AS A PROCESS MODERATOR}

In experiment 5, we tested a third moderator of the greater value ascribed to physical than digital goods and examined the likely underpinnings of the effect: whether differences in perceived control underlie the different capacity of digital and physical goods to garner psychological ownership (hypothesis 3). We propose that perceived control, an antecedent to psychological ownership (Peck and Shu 2009; Pierce et al. 2003), may be easier for consumers to establish for physical than for digital goods. We tested this hypothesis by measuring individual differences in NFC (Burger and Cooper 1979; Leotti, Iyengar, and Ochsner 2010), psychological ownership, and valuation of a physical or digital good. As being able to control one's environment is more important for some people than for others, we expected that differences in this need would influence the difference in psychological ownership garnered by physical and digital goods. As perceived control is an important antecedent of psychological ownership (Peck and Shu 2009; Pierce et al. 2003), if it is greater for physical than digital goods, then differences in psychological 
ownership for physical and digital goods should be greater for people with high NFC than for people with low NFC. And due to the value-enhancing effects of psychological ownership, differences in value ascribed to physical and digital goods should then be greater for people with high NFC than for people with low NFC.

In experiment 5, participants indicated their WTP and anticipated psychological ownership for either a physical or a digital copy of a popular book. We also measured individual differences in their NFC. In a test of moderated mediation, we expected that the greater valuation via psychological ownership that is attributed to physical than digital goods would be moderated by individual differences in NFC. Participants with a higher NFC should exhibit a greater difference in psychological ownership and value between physical and digital goods relative to participants with a lower NFC, who should show no difference in the psychological ownership and value they ascribed to physical and digital goods. Additionally we asked participants to make estimates of the production cost and retail price of the book they evaluated, so that we could statistically control for the possible effects of these factors on what participants were WTP for the book.

\section{Method}

Participants. Two hundred two Amazon Mechanical Turk workers $\left(45.5 \%\right.$ female, $M_{\text {age }}=35.90, \mathrm{SD}_{\text {age }}=$ 12.71 ) completed the experiment for $\$ 0.30$. They were randomly assigned to either the physical or the digital product condition.

Procedure. Participants in the physical condition read, "Imagine that printed copies of the new book by an author that you like are available for purchase." Participants in the digital condition read, "Imagine that digital copies of the new book by an author that you like are available for purchase. (Digital books are downloaded online.)" Then they indicated their WTP and anticipated psychological ownership $(\alpha=.96)$ for the book, as in experiment 2 , in counterbalanced order.

Next, on a separate screen, all participants answered the open-ended questions, "Please estimate the approximate cost of producing a single printed [digital] copy of the book that you considered previously in this survey (in USD)" and "In your opinion, what is the usual retail price of a printed [digital] copy of the book that you considered previously in the survey (in USD)?"

Participants then completed a four-item need-for-control scale (Rijk et al. 1998): "I prefer giving orders instead of receiving them"; "I prefer having control over what I do and the way I do it"; "I prefer doing my own planning"; "I prefer being able to set the pace of my tasks." Items were presented in random order, with responses made on five-point scales with the endpoints "strongly disagree" (1) and "strongly agree" (5) $(\alpha=.69)$. Finally, participants reported their age and gender.

\section{Results}

Neither question order nor their interaction with product format had an effect on WTP or psychological ownership. We thus collapsed across question order in all analyses reported here.

Because WTP, production cost, and retail price estimates were skewed (skewness $>2.00$ ) except for the retail price estimates of the digital book, these data were square root transformed; analyses on untransformed data yield similar results.

Participants were WTP significantly more for the printed book $\left(M_{\mathrm{SQRTWTP}}=\$ 4.36, \mathrm{SD}=1.33\right)$ than for the digital book $\left(M_{\mathrm{SQRTWTP}}=\$ 3.14, \mathrm{SD}=1.32 ; t(200)=6.56, p<\right.$ $.001, d=.93)$. Moreover, this difference was statistically significant $\left(F(1,198)=28.16, p<.001, \eta_{\mathrm{p}}^{2}=.13\right)$ when we controlled for the effects of the square root of retail price estimates $\left(F(1,198)=40.42, p<.001, \eta_{\mathrm{p}}^{2}=.17\right)$ and the square root of production cost estimates $(F(1,198)=$ $\left..83, p=.37, \eta_{\mathrm{p}}^{2}=.004\right)$. As predicted, participants also reported higher anticipated psychological ownership for the printed book $(M=6.18, \mathrm{SD}=.84)$ than for the digital book $(M=4.78, \mathrm{SD}=1.63 ; t(200)=7.69, p<.001, d=1.09)$.

In order to test whether differences in perceived control over physical and digital goods underlie the difference in their capacity to garner psychological ownership, we conducted a moderated mediation analysis. We examined whether individual differences in NFC moderate the $a$ path of our model in which differences in psychological ownership mediate the greater willingness to pay for physical than digital goods (figure 7). We tested the model with 5,000 bootstrap iterations, as in experiment 2. Product format was coded as in the previous studies (i.e., digital $=0$, physical $=1$ ).

As predicted, the indirect effect through psychological ownership was significant and greater for participants with higher NFC: indirect effects .21 [.07, .49], .32 [.15, .58], and .43 [.22, .75] for NFC levels 3.48, 4.04, and 4.61, respectively, corresponding to the mean NFC and plus or minus one standard deviation from the mean. The index of moderated mediation was significant $(95 \%$ CI $[.06, .44])$, indicating that NFC moderated the mediation through psychological ownership. The direct effect of product format was significant $(95 \%$ CI $[.18, .86])$, indicating partial mediation by psychological ownership.

The direction of the effects in the mediation analysis (figure 7) indicates that the influence of the physical format of the book on its capacity to garner psychological ownership was stronger for participants with higher NFC, which in turn contributed to higher WTP, even after the effects of retail price and production cost estimates were statistically controlled. 
FIGURE 7

MODERATED MEDIATION MODEL FOR THE SQUARE ROOT OF WILLINGNESS TO PAY IN EXPERIMENT 5

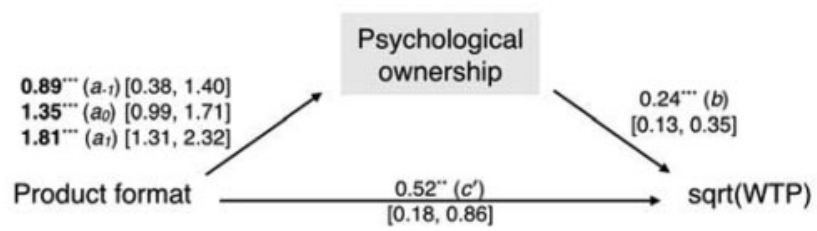

NOTE.-Psychological ownership partially mediated the effect of product format on WTP, but that mediation was moderated by NFC in experiment 5 . The three parameter estimates on the left of the figure indicate the conditional effects of format on ownership at the mean $\left(a_{0}\right)$ and plus/minus one SD from the mean $\left(a_{1} / a_{-1}\right)$ of NFC. The effects of the statistical controls, the square root of production cost estimate, and the square root of retail price estimate on ownership were $.01[-.07, .09]$ and $.01[-.10, .12]$, and on the square root of WTP were $.03[-.03, .09]$ and $.31^{* * *}[.22, .40]$, respectively. Bracketed numbers indicate $95 \%$ Cls. ${ }^{*} p<.05,{ }^{* *} p<.01,{ }^{* * *} p<.001$.

\section{Discussion}

Participants were WTP more for a new book by an author they enjoyed if it was offered in a physical than digital format, which was due, in part, to the greater capacity for physical than digital goods to garner psychological ownership. More important, the results of experiment 5 suggest that the greater capacity for physical than digital goods to garner psychological ownership is due to differences in perceived control over those goods. This hypothesis was supported by the moderated mediation of psychological ownership via individual differences in NFC. The meditating role of psychological ownership was present for participants with a higher NFC and absent for participants with a lower NFC.

In addition, the results provide evidentiary support that the greater value ascribed to physical than digital goods is not due to obvious differences in their perceived retail price or production costs. Participants in experiment 1 also estimated production costs of their souvenir photograph. Those estimates, however, included factors such as wages and materials such as the photograph and historical figure's costume, some of which participants may not have considered spontaneously. Experiment 5 specifically measured a more standard estimate of production cost, the cost of producing a single copy of the product. Still, neither production cost nor retail price estimates appeared to influence the mediating effect of psychological ownership on the relationship between product format and WTP.

\section{GENERAL DISCUSSION}

Digital goods possess many unique desirable features that their physical counterparts do not. Yet across a variety of products and elicitation measures, we find that people ascribe greater value to physical goods than digital goods. In a PWYW field study, tourists donated more money to charity in exchange for a physical than a digital souvenir photograph. Americans indicated higher purchase intention and WTP for physical than digital books and movies. Even business students indicated a higher WTP for physical than digital textbooks. We observed these differences when controlling for potential differences in perceived production costs (experiments 1 and 5), retail prices (experiments 3 and 5), resale value (experiments 1 and 5), and consumption utility and perceived permanence (experiment 2).

The greater establishment of psychological ownership appears to underlie the higher value ascribed to physical than digital goods. Anticipated psychological ownership mediated (experiments 2 and 5) the difference in their value, and antecedents and consequents of psychological ownership moderated the difference in their value (experiments 3 and 4). Furthermore, individual differences in psychological control-a basic underpinning of psychological ownership - moderated the mediating effect of psychological ownership on the greater value ascribed to physical than digital goods (experiment 5). Of course, there are likely to be other factors that contribute to this difference in value. Psychological ownership partially but did not fully mediate the greater value ascribed to physical than digital goods in experiments 2 and 5, suggesting that other, yet-unidentified factors may also play important roles in their difference in value.

In addition to further illustrating the important role that psychological ownership plays in the establishment of value (Beggan 1992; Morewedge and Giblin 2015; Pierce et al. 2003; Shu and Peck 2011), our experiments corroborate existing qualitative research suggesting that people value digital goods less than their physical counterparts (Belk 2013; Giles et al. 2007; McCourt 2005; Petrelli and Whittaker 2010; Siddiqui and Turley 2006). Moreover, the results rule out obvious differences in market value, transaction utility, feature-based utility, and consumption utility, thereby elucidating which of the many proposed mechanisms underlie the greater value of physical than digital goods.

\section{Theoretical Implications}

Our findings point out at least four new paths for consumer theory. First, the majority of research on psychological ownership to date has focused on person-oriented determinants from physical interactions with objects to internal temporary and chronic psychological processes and states (for reviews, see Belk 2013; Morewedge and Giblin 2015; Pierce, Kostova, and Dirks 2001; Shu and Peck 2011). Our findings demonstrate that object-oriented factors play a role in the capacity for objects to garner psychological ownership. Furthermore, our findings suggest that a variety of object-oriented factors influencing perceived 
control, such as the riskiness and autonomy of products, may influence the extent to which consumers can establish psychological ownership over those products (Waytz et al. 2010). Consumers may never establish the same degree of ownership for smart technologies (e.g., autonomous cars) as for less advanced manually controlled technologies (e.g., manual cars), for instance, because the selfcontrolling features of autonomous devices impair consumers' ability to feel like those devices are under their control.

Second, our findings contribute to the growing literature elucidating how psychological ownership influences the value of goods before their acquisition. They show how features of a good influence preacquisition extension of psychological ownership to the good, influencing both the value of the good and likelihood of acquisition. Our work shows that perceived changes in the present or future ownership status of a good (Brasel and Gips 2014; Ericson and Fuster 2011; Kim and Johnson 2014; Peck et al. 2013; Peck and Shu 2009; Reb and Connolly 2007) are not the sole determinants of the extent to which psychological ownership is extended to a good before it is acquired.

Third, our results inform the distinction between material and experiential purchases. Material purchases are objects of value, such as cars and furniture, whereas experiential purchases are events that last for only a limited time, such as vacations and concerts (Van Boven and Gilovich 2003). The main finding in this stream of research is that experiential purchases generally lead to more happiness than do material purchases (Carter and Gilovich 2010; Nicolao, Irwin, and Goodman 2009; Van Boven and Gilovich 2003). Our findings suggest that because experiential purchases are intangible, consumers may undervalue them because they may anticipate feeling less psychological ownership for material than experiential goods.

Last, an implication of our control account, to be tested by future research, is that consumers may exhibit a greater preference for physical relative to digital goods when their control is reduced, or when consumers adopt a prevention focus on avoiding risks (Higgins 1998). Their greater perceived control over physical goods may help restore their sense of control or reduce risk in uncertain circumstances or surroundings.

\section{Implications for Marketing Strategy}

Consumers have responded positively to the liquidity, practicality, and lower cost of digital goods, as indicated by these goods' proliferation throughout modern life (Bardhi et al. 2012; Denegri-Knott, Watkins, and Wood 2012). Still, digital goods have not replaced physical goods in any product category, including music, movies, and books. Given the growing market for digital goods (Goldfarb et al. 2015), our findings make at least four practical, actionable recommendations for marketing strategy.
First, the absence of this reliable difference in value for rented goods in experiment 3 suggests that firms offering goods in a subscription or rental format may not create more value for consumers by offering products in both physical and digital formats, assuming that consumers see the two formats as perfect substitutes (which they may not).

Second, our results may help explain why consumers generally view stealing physical goods to be morally wrong, but view the billion dollars' worth of digital piracy in which many of them engage to be morally acceptable (Lysonski and Durvasula 2008). Harm inflicted by an action is a basic determinant of the extent to which it is considered morally blameworthy (Gray, Young, and Waytz 2012). The lower value ascribed to digital than physical goods may imbue consumers with the perception that digital piracy is less harmful to companies and creative content producers than the analogous theft of a physical good. In other words, if consumers view the value of a pirated PDF of a book to be lower than the value of a stolen physical copy of a book, they may view its theft as a less severe moral violation and be more willing to steal it.

A third implication is that psychological ownership for digital goods is relatively weak, and the strengthening of psychological ownership is a potential means to increase their valuation. Skeuomorphism, adding unnecessary characteristics to digital goods so they resemble their physical counterparts, is a strategy used in the design of digital products and user interfaces (Page 2014). Apple employs it by displaying digital books on a virtual wooden shelf in its iBooks application. Our findings suggest elements of physical products that increase a feeling of psychological ownership may be most effective in increasing their desirability and value. Adding features that give consumers an increased feeling of control over the product (Pierce et al. 2003), such as interacting with the product by touching it (Brasel and Gips 2014; Peck et al. 2013; Peck and Shu 2009) or increasing their control over it through low-cost customization opportunities involving them in the product's production or design (Buechel and Janiszewski 2014; Fuchs, Prandelli, and Schreier 2010), should increase consumers' feelings of psychological ownership for digital goods, their perceived value, and the desirability of their adoption.

Fourth, links between psychological ownership and valuation are often contingent on self-enhancement (Beggan 1992; Dommer and Swaminathan 2013; Maddux et al. 2010; Morewedge and Giblin 2015). People with more favorable self-views may exhibit a stronger preference for physical relative to digital goods. There may also be cultural effects such that the disparity in value ascribed to physical and digital goods may be smaller in cultures with fewer self-enhancing tendencies (e.g., East Asian) than in cultures where self-enhancement is more acceptable and prevalent (e.g., Western Europe and North America; Maddux et al. 2010). 


\section{Conclusion}

The digitization of content and goods has tremendous potential to improve consumer welfare through means such as increasing access to new information and technology, reducing pecuniary costs and nonpecuniary costs such as transaction disutility, and reducing the impact of production on the environment (Goldfarb et al. 2015; Lehdonvirta 2012). Digital goods may be better suited for consumers in an increasingly mobile and liquid world (Bardhi et al. 2012). As digital goods continue to improve consumer welfare, however, their potential may face limits imposed by the architecture of cognition. Our findings illustrate how psychological ownership engenders a difference in the perceived value of physical and digital goods, yielding new insights into the relationship between consumers and their possessions.

\section{DATA COLLECTION INFORMATION}

The first author supervised the collection of data for all experiments by himself and research assistants in Boston and online from spring 2015 to spring 2017. The first author analyzed the data with the assistance of the second author. The second author ran the article through Statcheck.io, which found zero errors.

\section{REFERENCES}

Amazon (2016), “Ordering Prints," https://www.amazon.com/gp/ help/customer/display.html?nodeId=202070110.

Bardhi, Fleura, Giana M. Eckhardt, and Eric J. Arnould (2012), "Liquid Relationship to Possessions," Journal of Consumer Research, 39 (3), 510-29.

Beggan, James K. (1992), "On the Social Nature of Nonsocial Perception: The Mere Ownership Effect," Journal of Personality and Social Psychology, 62 (2), 229-37.

Belk, Russell W. (1988), "Possessions and the Extended Self," Journal of Consumer Research, 15 (2), 139-68.

_ (2013), "Extended Self in a Digital World," Journal of Consumer Research, 40 (3), 477-500.

Brasel, S. Adam and James Gips (2014), "Tablets, Touchscreens, and Touchpads: How Varying Touch Interfaces Trigger Psychological Ownership and Endowment," Journal of Consumer Psychology, 24 (2), 226-33.

Buechel, Eva C. and Chris Janiszewski (2014), "A Lot of Work or a Work of Art: How the Structure of a Customized Assembly Task Determines the Utility Derived from Assembly Effort," Journal of Consumer Research, 40 (5), 960-72.

Burger, Jerry M. and Harris M. Cooper (1979), "The Desirability of Control," Motivation and Emotion, 3 (4), 381-93.

Carter, Travis J. and Thomas Gilovich (2010), "The Relative Relativity of Material and Experiential Purchases," Journal of Personality and Social Psychology, 98 (1), 146-59.

Chatterjee, Promothesh, Caglar Irmak, and Randall L. Rose (2013), "The Endowment Effect as Self-Enhancement in Response to Threat," Journal of Consumer Research, 40 (3), 460-76.
Cohen, Peter, Robert Han, Jonathan Hall, Steven Levitt, and Robert Metcalfe (2017), "Using Big Data to Estimate Consumer Surplus: The Case of Uber," NBER Working Paper No. 22627.

Denegri-Knott, Janice, Rebecca Watkins, and Joseph Wood (2012), "Transforming Digital Virtual Goods into Meaningful Possessions," in Digital Virtual Consumption, Vol. 23, ed. Mike Molesworth and Janice Denegri-Knott, Oxford, UK: Routledge, 76-91.

Digital Entertainment Group (2016), "Second Quarter 2016 Home Entertainment Report" (August), http://degonline.org/.

Dommer, Sarah L. and Vanitha Swaminathan (2013), "Explaining the Endowment Effect Through Ownership: The Role of Identity, Gender, and Self-Threat," Journal of Consumer Research, 39 (5), 1034-50.

Ericson, Keith M. M. and Andreas Fuster (2011), "Expectations as Endowments: Evidence on Reference-Dependent Preferences from Exchange and Valuation Experiments," Quarterly Journal of Economics, 126 (4), 1879-907.

Fischer, David H. (1994), Paul Revere's Ride, New York: Oxford University Press.

Fuchs, Christoph, Emanuela Prandelli, and Martin Schreier (2010), "The Psychological Effects of Empowerment Strategies on Consumers' Product Demand," Journal of Marketing, 74 (1), 65-79.

Furby, Lita (1980), "The Origins and Early Development of Possessive Behavior," Political Psychology, 2 (1), 30-42.

Giles, David C., Stephen Pietrzykowski, and Kathryn E. Clark (2007), "The Psychological Meaning of Personal Record Collections and the Impact of Changing Technological Forms," Journal of Economic Psychology, 28 (4), 429-43.

Gilovich, Thomas, Amit Kumar, and Lily Jampol (2015), “A Wonderful Life: Experiential Consumption and the Pursuit of Happiness," Journal of Consumer Psychology, 25 (1), 152-65.

Gneezy, Ayelet, Uri Gneezy, Gerhard Riener, and Leif D. Nelson (2012), "Pay-What-You-Want, Identity, and SelfSignaling in Markets," Proceedings of the National Academy of Sciences of the United States of America, 109 (19), 7236-40.

Goldfarb, Avi, Shane M. Greenstein, and Catherine E. Tucker (2015), Economic Analysis of the Digital Economy, Chicago: University of Chicago Press.

Gray, Kurt, Liane Young, and Adam Waytz (2012), "Mind Perception Is the Essence of Morality," Psychological Inquiry 23 (2), 101-24.

Hayes, Andrew F. (2013), Introduction to Mediation, Moderation, and Conditional Process Analysis: A Regression-based Approach, New York: Guilford Press.

Henley, Nancy (1973), "Power, Sex, and Nonverbal Communication," Berkeley Journal of Sociology, 18, 1-26.

Higgins, E. Tory (1998), "Promotion and Prevention: Regulatory Focus as a Motivational Principle," in Advances in Experimental Social Psychology, Vol. 30, ed. M. P. Zanna, New York: Academic Press, 1-46.

Kim, Kyungmi and Marcia K. Johnson (2014), "Extended Self: Spontaneous Activation of Medial Prefrontal Cortex by Objects That Are 'Mine," Social Cognitive and Affective Neuroscience 9 (7), 1006-12.

Lehdonvirta, Vili (2012), "A History of the Digitalization of Consumer Culture: From Amazon through Pirate Bay to FarmVille," in Digital Virtual Consumption, Vol. 23, ed. Mike Molesworth and Janice Denegri-Knott, Oxford, UK: Routledge, 11-28. 
Leotti, Lauren A., Sheena S. Iyengar, and Kevin N. Ochsner (2010), "Born to choose: The origins and value of the need for control," Trends in Cognitive Sciences, 14 (10), 457-63.

Liberman, Nira and Yaacov Trope (1998), "The Role of Feasibility and Desirability Considerations in Near and Distant Future Decisions: A Test of Temporal Construal Theory," Journal of Personality and Social Psychology, 75 (1), 5-18.

List, John A. (2003), "Does Market Experience Eliminate Market Anomalies?" Quarterly Journal of Economics, 118 (1), 41-71.

Lysonski, Steven and Srinivas Durvasula (2008), "Digital Piracy of MP3s: Consumer and Ethical Predispositions," Journal of Consumer Marketing, 25 (3), 167-78.

Maddux, William W., Haiyang Yang, Carl Falk, Hajo Adam, Wendi Adair, Yumi Endo, Ziv Carmon, and Steven J. Heine (2010), "For Whom Is Parting with Possessions More Painful? Cultural Differences in the Endowment Effect," Psychological Science, 21 (12), 1910-17.

McCourt, Tom (2005), "Collecting Music in the Digital Realm," Popular Music and Society 28 (2), 249-52.

Mintel (2009), "Still and Video Cameras," http://academic.mintel. com/display/393596/.

Molesworth, Mike and Janice Denegri-Knott (2013), "Digital Virtual Consumption as Transformative Space," in Routledge Companion to Digital Consumption, ed. Russell Belk and Rosa Llamas, London: Routledge, 223-34.

Morewedge, Carey K. and Colleen E. Giblin (2015), "Explanations of the Endowment Effect: An Integrative Review," Trends in Cognitive Sciences, 19, (6), 339-48.

Morewedge, Carey K., Lisa L. Shu, Daniel T. Gilbert, and Timothy D. Wilson (2009), "Bad Riddance or Good Rubbish? Ownership and Not Loss Aversion Causes the Endowment Effect," Journal of Experimental Social Psychology, 45 (4), 947-51.

Morewedge, Carey K., Simone Tang, and Richard P. Larrick (2016), "Betting Your Favorite to Win: Costly Reluctance to Hedge Desired Outcomes," Management Science, http://pub sonline.informs.org/doi/pdf/10.1287/mnsc.2016.2656.

Nicolao, Leonardo, Julie R. Irwin, and Joseph K. Goodman (2009), "Happiness for Sale: Do Experiential Purchases Make Consumers Happier than Material Purchases?" Journal of Consumer Research, 36 (2), 188-98.

Odom, William, John Zimmerman, and Jodi Forlizzi (2011), "Teenagers and Their Virtual Possessions: Design Opportunities and Issues," Proceedings of the SIGCHI Conference on Human Factors in Computing Systems, ACM, 1491-500.

Page, Tom (2014), "Skeuomorphism or Flat Design: Future Directions in Mobile Device User Interface (UI) Design Education," International Journal of Mobile Learning and Organization, 8 (2), 130-42.

Peck, Joann, Victor A. Barger, and Andrea Webb (2013), "In Search of a Surrogate for Touch: The Effect of Haptic Imagery on Perceived Ownership," Journal of Consumer Psychology, 23 (2), 189-96.

Peck, Joann and Suzanne B. Shu (2009), "The Effect of Mere Touch on Perceived Ownership," Journal of Consumer Research, 36 (3), 434-47.

Pena-Marin, Jorge and Rajesh Bhargave (2016), "Lasting Performance: Round Numbers Activate Associations of Stability and Increase Perceived Length of Product Benefits," Journal of Consumer Psychology, 26 (3), 410-16.

Perez, Sarah (2016), "Amazon Undercuts Rivals with Launch of New Photo Printing Service, Amazon Prints," https://tech crunch.com/2016/09/22/amazon-undercuts-rivals-withlaunch-of-new-photo-printing-service-amazon-prints/.

Perkins, Andrew W. and Mark R. Forehand (2012), "Implicit SelfReferencing: The Effect of Nonvolitional Self-Association on Brand and Product Attitude," Journal of Consumer Research, 39 (1), 142-56.

Petrelli, Daniela and Steve Whittaker (2010), "Family Memories in the Home: Contrasting Physical and Digital Mementos," Personal and Ubiquitous Computing, 14 (2), 153-69.

Pew Research Center (2016), "Book Reading 2016" (September), http://www.pewinternet.org/.

Pierce, Jon L., Tatiana Kostova, and Kurt T. Dirks (2001), "Toward a Theory of Psychological Ownership in Organizations," Academy of Management Review, 26 (2), 298-310.

- (2003), "The State of Psychological Ownership: Integrating and Extending a Century of Research," Review of General Psychology, 7 (1), 84-107.

Reb, Jochen and Terry Connolly (2007), "Possession, Feelings of Ownership, and the Endowment Effect," Judgment and Decision Making, 2 (2), 107-14.

Rijk, Angelique E., Pascale M. Le Blanc, Wilmar B. Schaufeli, and Jan Jonge (1998), "Active coping and need for control as moderators of the job demandcontrol model: Effects on burnout." Journal of Occupational and Organizational Psychology, 71 (1), 1-8.

Said, Carolyn (1990), "Dycam Model 1: The First Portable Digital Still Camera," MacWeek, 4 (35), 34.

Sen, Sankar and Eric J. Johnson (1997), "Mere-Possession Effects without Possession in Consumer Choice," Journal of Consumer Research, 24 (1), 105-17.

Shu, Suzanne B. and Joann Peck (2011), "Psychological Ownership and Affective Reaction: Emotional Attachment Process Variables and the Endowment Effect," Journal of Consumer Psychology, 21 (4), 439-52.

Siddiqui, Shakeel and Darach Turley (2006), "Extending the Self in a Digital World," in Advances in Consumer Research, Vol. 33, ed. Connine Pechmann and Linda Price, Duluth, MN: Association for Consumer Research, 647-48.

Van Boven, Leaf and Thomas Gilovich (2003), "To Do or to Have? That Is the Question," Journal of Personality and Social Psychology, 85 (6), 1193-202.

Waytz, Adam, Carey K. Morewedge, Nicholas Epley, George Monteleone, Jia-Hong Gao, and John T. Cacioppo (2010), "Making Sense by Making Sentient: Effectance Motivation Increases Anthropomorphism," Journal of Personality and Social Psychology, 99 (3), 410-35.

Weiss, Liad and Gita V. Johar (2013), "Egocentric Categorization and Product Judgment: Seeing Your Traits in What You Own (and Their Opposite in What You Don't)," Journal of Consumer Research, 40 (1), 185-201.

(2016), "Products as Self-Evaluation Standards: When Owned and Unowned Products Have Opposite Effects on SelfJudgment," Journal of Consumer Research, 42 (6), 915-30.

Werner, Carol M., Barbara B. Brown, and Gary Damron (1981), "Territorial Marking in a Game Arcade," Journal of Personality and Social Psychology, 41 (6), 1094-104.

Wilcox, Rand R. (2010), Fundamentals of Modern Statistical Methods: Substantially Improving Power and Accuracy, Berlin: Springer Science \& Business Media.

Zhao, Xinshu, John G. Lynch Jr., and Qimei Chen (2010), "Reconsidering Baron and Kenny: Myths and Truths about Mediation Analysis," Journal of Consumer Research, 37 (2), 197-206. 